\title{
Prevalence and Maternal Concerns of Exclusive Breast Feeding in Liby- an Women in Albaida City
}

\author{
Mohamed Thabet Ali *, Faiza M. Ali \\ Department of Pediatrics, Omar Al-Mukhtar University, Al-Bayda-Libya
}

Received: 30 January 2019 / Accepted: 25 June 2019

Doi: https://doi.org/10.54172/mjsc.v34i2.79

\begin{abstract}
Exclusive breastfeeding (EBF) is strongly recommended by the World Health Organization, United Nation Children's Fund (UNICEF), and American Academy of Pediatrics during the first six months of life. Breastfeeding should continue up to two years for optimal growth and development while it is suggested to start supplementary foods beginning from the seventh month. The study aimed to determine the frequency and examine the affecting factors of EBF in infants who attended the pediatrics outpatient clinic in Althawra Hospital in Albaida city, Libya. A crosssectional study was conducted in eight months period among 223 breastfeeding mothers, with infants aged 6-24 months, who attended the pediatrics Outpatient clinic. Mothers' perceptions about breastfeeding, complementary feeding practices, and demographic characteristics were collected by interviews with them. EBF periods were 1-45 weeks, Median week was 17 weeks. Six months EBF rate was $32,28 \%$. Younger mother $(\leq 20)$ or older $(\geq 35)$ ages, and mothers having chronic diseases had a shorter median week of EBF. The median duration of breastfeeding was 9 months $(0-24$ months). The most frequent reason of the early interruption of EBF was, according to mother's perceptions, for having inadequate breast milk $(50.3 \%)$. The study indicates that the frequency of 6 months EBF (32,28\%) and the median duration of breastfeeding (17 weeks) are low in Albaida. A local strategy must be developed to overcome mothers negative perceptions about EBF in the first 6 months of age.
\end{abstract}

Keywords: Exclusive breastfeeding, Infant, Nutrition

\section{INTRODUCTION}

Exclusive breastfeeding is important for healthy growth and development in young infants (WHO, 2003). It is one of the interventions that reduce infant morbidity and mortality and allows the infant to receive breast milk only with no other liquids or foods, not even water, except drops of syrups, vitamins, minerals or medicines (Pediatrics, 2005). Muslim countries are expected to support, promote, and protect breastfeeding based on religion. Infants exclusively breastfed for 6 months presented with fewer infectious episodes such as acute respiratory infection, acute otitis media, and gastroenteritis than their partially breastfed or non-breastfed peers (James \& Lessen, 2009). To enable mothers for establishing and sustaining exclusive breastfeeding for six months, WHO and UNICEF recommended early initiation of breastfeeding within the first hour of infant life. The infant only receives breast milk without any additional food or drink, not even water, and breastfeeding on demand. (Organization, 2010). In Libya, we have limited data about breastfeeding practices; hence, understanding the factors that influence EBF is essential to help in the development of strategies to promote EBF practices in Libya. The purpose of the present study is to determine EBF frequency in infants who attended a pedi-

*Corresponding Author: Mohamed Thabet Ali, alkwafi65@yahoo.com, Department of Pediatrics, Omar Almukhtar University, Albaida - Libya. 
atric outpatient clinic in Albaida city to examine factors affecting EBF and to determine the measures to increase EBF prevalence to $90 \%$ which is recommended by the WHO

\section{MATERIALS AND METHODS}

Albaida city is in the center of Aljabal Alakhdar, eastern part of Libya. This study had been conducted in a pediatrics outpatient clinic in Althawra Teaching Hospital over eight months period (from May 2018 to January 2019).

The study population consisted of children from this area that were enrolled in this prospective and cross-sectional study. Healthy breastfed infants without oral feeding problems, ages between 6-24 months, who attended the pediatric outpatient clinic during the eight months period were included in the study. Mothers signed written informed consent. The age, sex, birth weight, recent anthropometries of the babies, time of weaning, the type of the first food other than breast milk, the time of interrupting $\mathrm{EBF}$, perceptions of mothers to interrupt EBF, and the duration of breastfeeding were noted with a standard interview questionnaire sheet which was developed and used by the researchers after reviewing the related literatures that assessed prevalence and maternal concerns about exclusive breastfeeding. Demographic features of the mother including age ( $\leq 20$ years, $20-34$ years, and $\geq 35$ years old), working status (housewife or working), education level (primary, secondary, university graduate), economic level (low, middle, high), habit, existence of a chronic disease, and the number and type of deliveries were also determined.

\section{Analytical analysis}

The data obtained from the study were analyzed with SPSS 15.0. Categorical values were compared with the Chi-square test. A p-value of less than 0.05 was considered significant.

\section{RESULTS}

Mean age of the 223 infants comprising the study population was 6-24 months, $44,39 \%$ of them were girls $(n=99)$. Overall six months EBF frequency was $32,28 \%$. When the factors that affected interrupting EBF were investigated, the incidence of interrupting EBF was higher among mothers with higher income $(68.4 \%)$ than mothers with middle income (67.97\%), and low income (65.38\%) although this difference was not statistically significant $(\mathrm{p}=0.23)$ (Table 1). The median age of EBF was 17 weeks (1-45 weeks). Mothers between age 20- 34.9 years had a longer median duration of EBF ( $p=0.001)$ (Table 3). Regarding Mother's education level, poorly educated mothers have the shortest median duration of EBF (Fig 2). Mothers with chronic diseases $(n=36)(16.1)$ interrupted EBF earlier than mothers without chronic diseases $(p=0.01)$. These chronic diseases included diabetes mellitus, asthma, goiter, and hypertension. Mothers who interrupted EBF had a shorter median duration of breastfeeding (median: 10, range 0-24 months) than EBF group (median: 14, range 624 months) ( $p=0.001)$. Mothers who interrupted EBF were asked why they had introduced supplementary foods earlier. The most frequent answer was mother's perceptions of having inadequate breast milk (50.3\%) (Table 2). The most frequent first complementary feeding given to the baby by EBF mothers was rice (29\%), whereas it was a commercial infant formula $(33 \%)$ among non-EBF mothers $(p=0.001)$. 


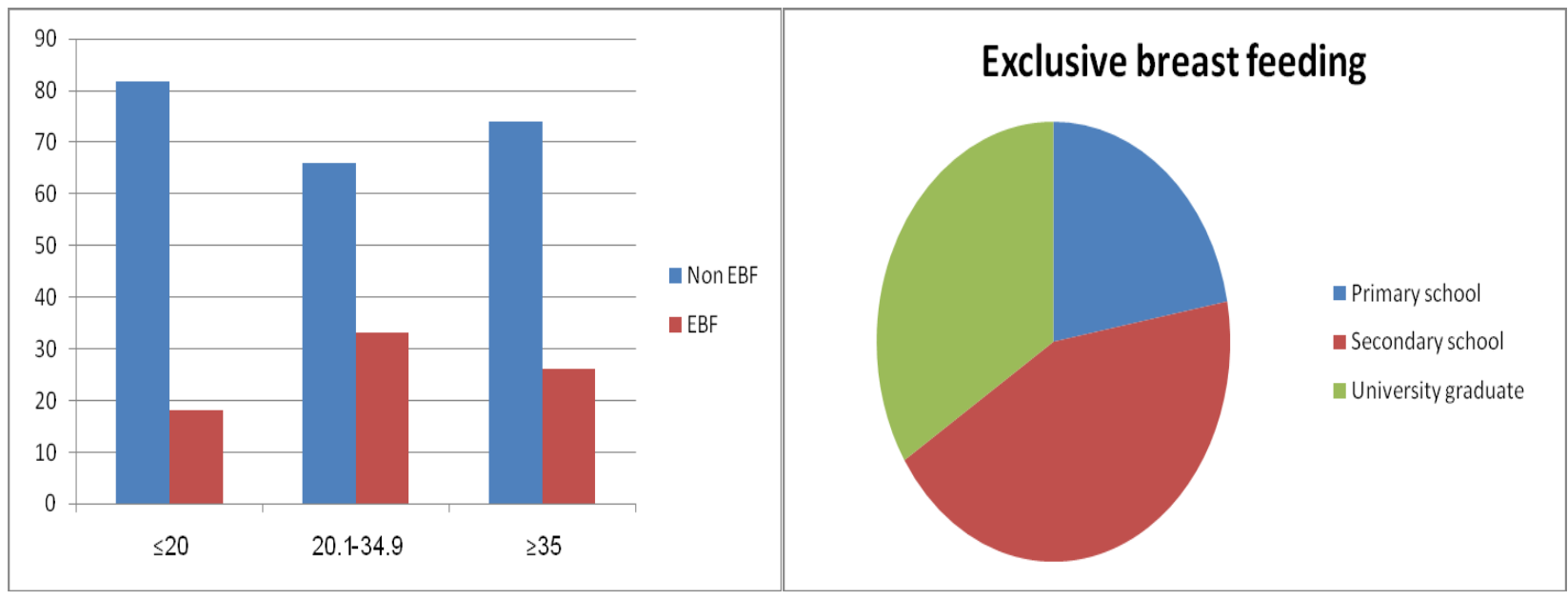

Fig (1). Mothers age (years) and EBF

Fig (2). Mothers education level vs EBF

Table (1). Characteristics of the EBF and non-EBF babies

\begin{tabular}{|c|c|c|c|c|}
\hline & & \multicolumn{2}{|c|}{ Exclusively breastfed infants } & \multirow[t]{3}{*}{$\mathrm{P}$} \\
\hline & & No & Yes & \\
\hline & & n $151(67.7) \%$ & n $72(32,28) \%$ & \\
\hline \multirow[t]{2}{*}{ Gender } & Boy & $76(61,29)$ & $48(38.7)$ & \\
\hline & Girl & $75(75,7)$ & $24(24.2)$ & \\
\hline \multirow[t]{3}{*}{ Mother age (yr) } & $\leq 20$ & $9(81.8)$ & $2(18.2)$ & 0.090 \\
\hline & $20.1-34.9$ & $125(66.1)$ & $64(33.9)$ & \\
\hline & $\geq 35$ & $17(73.9)$ & $6(26.1)$ & \\
\hline \multicolumn{5}{|c|}{ Mother's working status } \\
\hline & Housewife & $8(66.6)$ & $4(33.4)$ & 0.93 \\
\hline & Employed & $143(67.7)$ & $68(32.3)$ & \\
\hline \multicolumn{5}{|c|}{ Mother's education level } \\
\hline & mary school & $13(81.25)$ & $3(18.75)$ & 0.65 \\
\hline & ondary school & $79(63.2)$ & $46(36.8)$ & \\
\hline & versity graduate & $59(71.9)$ & $23(28.1)$ & \\
\hline \multicolumn{5}{|c|}{ Mother's chronic diseases } \\
\hline & Present & $30(76.9)$ & $9(23.1)$ & 0.175 \\
\hline & Absent & $121(65.7)$ & $63(34.3)$ & \\
\hline \multicolumn{5}{|c|}{ Economic level of the family } \\
\hline & Low & $17(65.38)$ & $9(34.62)$ & 0.23 \\
\hline & Middle & $121(67.97)$ & $57(32.03)$ & \\
\hline & High & $13(68.4)$ & $6(31.6)$ & \\
\hline \multicolumn{4}{|l|}{ Order of child } & 0.386 \\
\hline & Second or more & $83(65.35)$ & $44(34.65)$ & \\
\hline
\end{tabular}


Table (2). Perceptions of non-EBF mothers about why they had interrupted EBF ( $\mathrm{n}=151)$.

\begin{tabular}{lcc}
\hline \hline Reason & Number & $\%$ \\
\hline Breast milk was inadequate & 76 & 50.3 \\
Infant does not suck & 23 & 15.2 \\
Mother's own decision & 4 & 2,6 \\
Infant had a health problem & 5 & 3.3 \\
Infant had inadequate weight gain & 27 & 17.8 \\
Being twin & 3 & 1.9 \\
Mother's health problems & 7 & 6.6 \\
Mother was pregnant & 6 & 3.9 \\
Total & 151 & 100 \\
\hline \hline
\end{tabular}

Table (3). Factors affecting median week of EBF

\begin{tabular}{|c|c|c|c|c|}
\hline Characteristic & & $\begin{array}{l}\mathrm{n},(\%) \\
\quad(\mathrm{n}=223)\end{array}$ & Median week of EBF & $\mathrm{p}$ \\
\hline \multirow[t]{2}{*}{ Gender } & Boy & $124(55.6)$ & 17 & \\
\hline & Girl & $99(44.4)$ & 16 & \\
\hline \multicolumn{5}{|c|}{ Mother's age (years) } \\
\hline & $\leq 19$ & $8(3.6)$ & 14 & 0.001 \\
\hline & $20.1-34.9$ & $192(86)$ & 19 & \\
\hline & $\geq 35$ & $23(10.4)$ & 15 & \\
\hline \multicolumn{5}{|c|}{ Mother's working status } \\
\hline & Housewife & $12(5.4)$ & 20 & \\
\hline & Employed & $211(94.6)$ & 17 & \\
\hline \multicolumn{5}{|c|}{ Mother's education level } \\
\hline & Primary school & $16(7.2)$ & 19 & \\
\hline & Secondary school & $125(56)$ & 16 & \\
\hline & University graduate & $82(36.8)$ & 20 & \\
\hline \multicolumn{5}{|c|}{ Mather's chronic diseases } \\
\hline & Present & $36(16.1)$ & 11 & 0.0046 \\
\hline & Absent & $187(83.9)$ & 18 & \\
\hline \multicolumn{5}{|l|}{ Economic level } \\
\hline & $\begin{array}{l}\text { Low } \\
\text { Middle }\end{array}$ & $\begin{array}{l}26(11.7) \\
178(79.8)\end{array}$ & $\begin{array}{l}24 \\
17\end{array}$ & \\
\hline & High & $19(8.5)$ & 17 & \\
\hline
\end{tabular}

\section{DISCUSSION}

The reasons why mothers introduced foods earlier and the duration of breastfeeding were investigated in Libyan infants in our region, in Albaida city. In the present study sample, the frequency of six months EBF was $32 \%$, the mean EBF was 3.6 months, and the predominant EBF (received breast milk and plain water, water-based liquids, and/or juice only (excludes other milk)) was 4.2 months for all. A previous study in Benghazi- Libya showed that mixed feeding (breast plus artificial) was practiced by most of the mothers (61.5 to $79.2 \%)$ starting from 4 months to 24 months after birth (Shembesh, Balo, \& Singh, 1997). In mothers with chronic health problems, breastfeeding for more than six months was found to be only $23.1 \%$ compared to $34.3 \%$ for infants of mothers who did not have a disease. These results suggest that chronic maternal diseases are associated with low breastfeeding rates because of social and economic inequalities which 
worsen pregnancy and child-related outcomes. In some international studies, mothers with a chronic illness like diabetes and low EBF rates were found to be due to the factors including infants admission to the neonatal intensive care unit, and maternal- infant separation (OzaFrank, Chertok, \& Bartley, 2015). In another study, mothers concerns about illness or the need to take medicine were found to be one of the main reasons for the early termination of breastfeeding (Odom, Li, Scanlon, Perrine, \& Grummer-Strawn, 2013). So, Health care services should especially take into account the needs of mothers with chronic diseases, and to inform about the misconceptions about breastfeeding and support them. Also in our study group, mothers aged $\leq 20$ years had a shorter EBF duration than mothers aged between 2035 years (Fig 1). The breastfeeding rate among adolescent mothers (aged $<20$ years) in the US was reported to be low and has been dropping (Smith, Coley, Labbok, Cupito, \& Nwokah, 2012). The stated reasons for this age group were poor breastfeeding knowledge and skills, inadequate health care, being unprepared for the demands of motherhood. When non-EBF mothers were asked why they had interrupted $\mathrm{EBF}$, the most frequent reasons were the thought of not producing adequate breast milk $(50.3 \%)$ and that the infant does not suck (15.2\%). Compared to results from other countries, Maternal anxiety of inadequate breast milk was stated to be the main reason to stop EBF in Sri Lanka (Perera, Abeyweera, Fernando, Warnakulasuriya, \& Ranathunga, 2012). In Turkey, the most frequent reason was inadequate breast milk (42.6\%) (Neslihan, Rukiye, \& Y1ldiz, 2015). In Iran, the most frequently cited reasons for mothers for discontinuing EBF were physicians recommendation (54\%) and insufficient breast milk (28\%) (Olang, Heidarzadeh, Strandvik, \& Yngve, 2012). In the US, mothers who discontinued EBF were more likely to have experienced problems with their infant latching on or sucking or reported that a health care provider recommended formula supplementation(Taveras et al., 2004). Physicians and other health professionals have an important role to play in encouraging and supporting mothers to maintain breastfeeding. More than $95 \%$ of women are biologically capable of producing a sufficient quantity of milk or are able to accomplish adequate infant weight gain through breastfeeding alone. Anyhow, when a mother perceives that she is not providing an adequate quality or quantity of milk to her infant, she is likely to stop breastfeeding regardless of the infant's age (Odom et al., 2013).

\section{CONCLUSION}

In our study group, EBF rates and duration of breastfeeding was found to be low among breastfeeding mothers who attended outpatient pediatric clinics. Children were unnecessarily introduced to supplementary foods earlier although mothers breast milk was adequate. The study indicated that the frequency of 6 months EBF (32.28\%) and the median duration of breastfeeding (9 months) are low in our region, in Albaida city. We must develop a local strategy to overcome mothers' negative perceptions about EBF by increasing interviews with them about breastfeeding. It is essential to educate new mothers and prospective mothers about infant feeding. We believe that many health problems can be prevented by minimizing mistakes made in infant nutrition.

\section{REFERENCES}

James, D., \& Lessen, R. (2009). Position of the American Dietetic Association: promoting and supporting breastfeeding. Journal of the American Dietetic Association, 109(11), 19261942.

Global Strategy for Infant and Young Child Feeding, World Health Organization, Geneva. (2003). Available at: htp://www.who.int/nutriton/topics/exclu 
sive_breasteeding/en/.

December 2013

Neslihan, E., Rukiye, S. U., \& Yıldız, T. M. A. D. (2015). Frequency and Demographics of Exclusive Breastfeeding in Turkish Women in Ankara. Acta Med Anatol, 3(3), 92-98.

Odom, E. C., Li, R., Scanlon, K. S., Perrine, C. G., \& Grummer-Strawn, L. (2013). Reasons for earlier than desired cessation of breastfeeding. Pediatrics, 131(3), e726-e732.

Olang, B., Heidarzadeh, A., Strandvik, B., \& Yngve, A. (2012). Reasons given by mothers for discontinuing breastfeeding in Iran. International breastfeeding journal, $7(1), 7$.

Organization, W. H. (2010). World health statistics 2010: World Health Organization.

Oza-Frank, R., Chertok, I., \& Bartley, A. (2015). Differences in breast-feeding initiation and continuation by maternal diabetes status. Public health nutrition, 18(4), 727-735.

Pediatrics, A. A. o. (2005). Policy statement breastfeeding and the use of human milk. Pediatrics, 115, 496-506.

Perera, P. J., Abeyweera, N. T., Fernando, M. P., Warnakulasuriya, T. D., \& Ranathunga, N. (2012). Prevalence of dental caries among a cohort of preschool children living in Gampaha district, Sri Lanka: A descriptive cross sectional study. BMC Oral Health, 12(1), 49 .

Shembesh, N. M., Balo, N. N. M., \& Singh, R. (1997). Breast-feeding and weaning patterns in Benghazi, Libyan Arab Jamahiriya.
Smith, P. H., Coley, S. L., Labbok, M. H., Cupito, S., \& Nwokah, E. (2012). Early breastfeeding experiences of adolescent mothers: a qualitative prospective study. International breastfeeding journal, 7(1), 13.

Taveras, E. M., Li, R., Grummer-Strawn, L., Richardson, M., Marshall, R., Rêgo, V. H., . . . Lieu, T. A. (2004). Opinions and practices of clinicians associated with continuation of exclusive breastfeeding. Pediatrics, 113(4), e283e290. 
معدل انتشار الرضاعة الطبيعية الحصرية ومخاوف الأمهات بشأنها لاى النساء الليبيات في مدينة البيضاء محمد ثابت علي*، فائزة محمد علي قسم طب الأطفال، كلية الطب البشري، جامعة عمر الدختار-ليييا تاريخ الاستلام: 30 يناير 2019 / ناريخ القبول: 25 يونيو 2019 https://doi.org/10.54172/mjsc.v34i2.79:Doi

المستخلص: توصي منظمة الصحة العالمية وصندوق الأمم المتحدة للطفولة (اليونيسيف) والأكاديمية الأمريكية لطب الأطفال

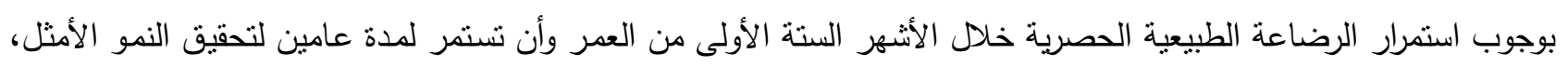

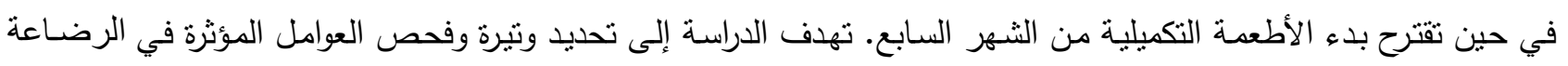

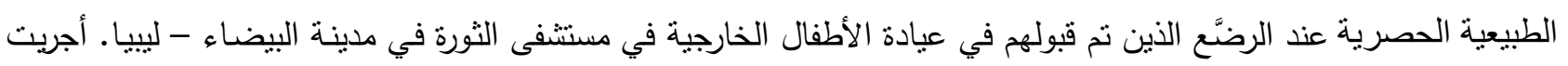

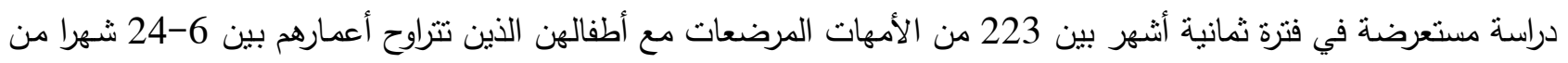

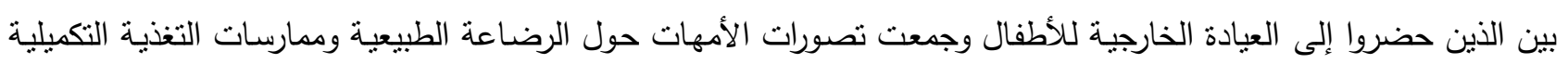

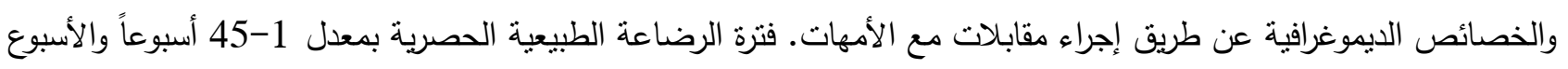

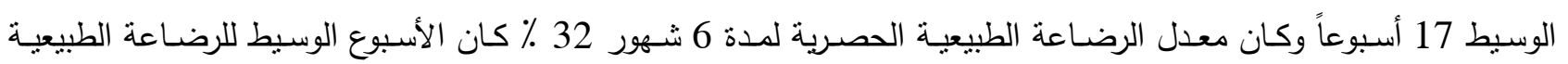

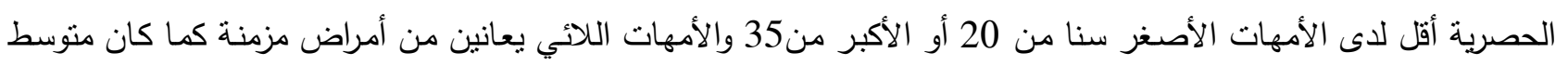

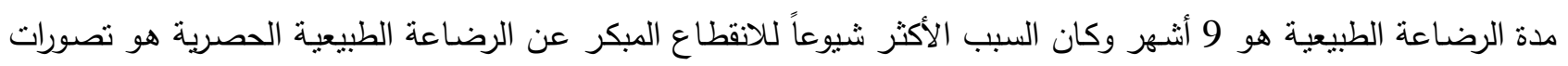

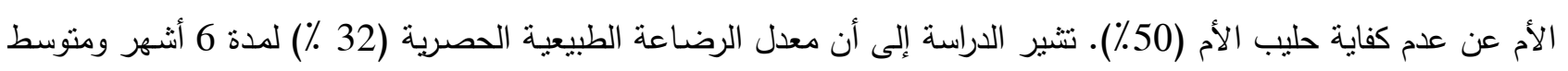

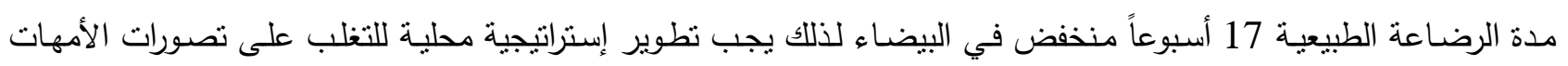

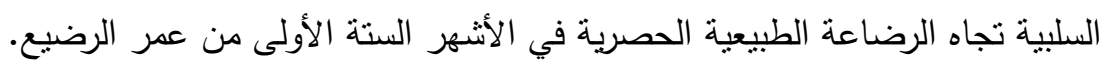
الكلمات المفتاحية: الرضاعة الطبيعية؛ الحصرية؛ رضيع؛ تغذية. 